\title{
Erratum to: Is Child to Adult as Victim is to Criminal?
}

\section{Social Policy and Street-Based Sex Work in the USA}

\author{
Anthony Marcus • Robert Riggs • Amber Horning • \\ Sarah Rivera $\cdot$ Ric Curtis $\cdot$ Efram Thompson
}

Published online: 17 December 2011

(C) Springer Science+Business Media, LLC 2011

\section{Erratum to: Sex Res Soc Policy \\ DOI 10.1007/s13178-011-0070-1}

The following text was inadvertently omitted at the end of the article:

Acknowledgment This study was made possible through a grant from the Office of Juvenile Justice and Delinquency Prevention of the U.S. Department of Justice. The opinions, findings, and conclusions or recommendations expressed in this publication are those of the authors and do not necessarily reflect the positions or policies of the Department of Justice.

The online version of the original article can be found at http://doi.dx. org/10.1007/s13178-011-0070-1.

A. Marcus $(\bowtie) \cdot$ R. Riggs $\cdot$ A. Horning $\cdot$ S. Rivera $\cdot$ R. Curtis John Jay College of the City University of New York, 899 Tenth Avenue Room 433T,

New York, NY 10019, USA

e-mail: amarcus@jjay.cuny.edu

R. Riggs

e-mail: robert.riggs@jjay.cuny.edu

A. Horning

e-mail: ahorning@jjay.cuny.edu

S. Rivera

e-mail: sarahbrivera@yahoo.com

R. Curtis

e-mail: rcurtis@jjay.cuny.edu

A. Marcus $\cdot$ R. Riggs $\cdot$ S. Rivera $\cdot$ R. Curtis $\cdot$ E. Thompson

Social Networks Research Group,

899 Tenth Avenue Room 433T,

New York, NY 10019, USA 